\title{
Penyelidikan Intrusi Air Laut pada Air Tanah dengan Metode Resistivitas 2D di Daerah Surabaya Timur
}

\author{
Rizky Rahmadi Wardhana, Dwa Desa Warnana, dan Amien Widodo \\ Jurusan Teknik Geofisika, Fakultas Teknik Sipil dan Perencanaan, Institut Teknologi Sepuluh Nopember (ITS) \\ Jl. Arief Rahman Hakim, Surabaya 60111 Indonesia \\ e-mail:dwa_desa@geofisika.its.ac.id
}

\begin{abstract}
Abstrak-Kawasan Surabaya Timur telah mengalami intrusi air laut dan berdampak pada akuifer air tanah sehingga memiliki kualitas air dengan adanya kadar garam yang terdapat pada sumur penduduk sekitar. Masalah adanya dugaan intrusi air laut ini telah diidentifikasi dengan menggunakan metode geolistrik dengan menggunakan konfigurasi wenner-schlumberger yang terletak di kawasan Surabaya Timur yang bertujuan untuk mengidentifikasi adanya intrusi air laut. Pengambilan data telah dilakukan pada kawasan Surabaya Timur saja. Data sumur juga dilakukan pengambilan sampel untuk mendapatkan hasil parameter air berupa elevasi muka air tanah, Salinitas, TDS, pH, dan Konduktivitas. Akuisisi data geolistrik dilakukan pada 3 titik lokasi yaitu Sutorejo, Klampis, dan ITS dengan menggunakan metode Resistivitas 2D dan Induced Polarization. Tahapan dari pengolahan data menggunakan perangkat lunak Res2Dinv. Berdasarkan hasil interpretasi pada daerah peneltian Sutorejo, pada kedalaman 0.6-3,5 meter atau pada perlapisan paling atas diduga terjadi intrusi air laut dengan nilai resistivitas 0.734-6.31 ohm.m yang terdapat pada bagian tengah hingga Timur Laut. Dugaan ini juga didukung dari hasil penelitian dari metode Induced Polarization yang menujukkan nilai 0.202 msec pada kedalaman 0.6-3.5 meter.
\end{abstract}

Kata Kunci-Akuifer, Intrusi Air Laut, Resistivitas, Surabaya Timur.

\section{PENDAHULUAN}

$\mathrm{K}$ AWASAN Surabaya merupakan daerah perkotaan yang terletak di daerah pantai yang merupakan delta dari Sungai Brantas. Kota Surabaya adalah kota dengan keterbatasan air bersih yang dikarenakan terjadinya penurunan kualitas air yang cukup signifikan. Permasalahan yang ditimbulkan dalam penurunan kualitas air ini diduga adanya keberadaan air tanah yang memiliki kualitas asin. Karena adanya air tanah dengan kualitas asin, maka menyebabkan peningkatan kadar salinitas pada air sumur, sehingga warga banyak yang mengeluhkan akan hal ini. Beberapa upaya dari warga seperti pembuatan sumur gali yang hanya mampu di kedalaman hingga $10 \mathrm{~m}$, warga hanya mendapatkan air sumur dengan kualitas asin. Bahkan di beberapa tempat juga kerap ditemukan air dengan memiliki kualitas yang payau. Tentunya hal ini ada kaitannya dengan adanya intrusi air laut pada akuifer khususnya di Surabaya Timur.

Penelitian ini dilakukan untuk melakukan penyelidikan pada akuifer air tanah dengan menggunakan metode Resistivitas 2D. Penelitian ini diharapkan bisa menghasilkan suatu perlapisan akuifer perlapisan tanah bawah permukaan. Setelah itu juga terdapat penampang dari Induced Polarization yang digunakan untuk melakukan perbandingan data dan akan dianalisis serta identifikasi akuifer air tanah.

\section{TINJAUAN PUSTAKA}

\section{A. $\quad$ Metode Resistivitas 2D}

Teori dasar yang digunakan pada metoda resistivitas ini adalah hokum ohm yang menyatakan, arus yang mengalir (I) pada suatu medium adalah sebanding dengan voltage (V) yang terukur dan berbanding terbalik dengan resistansi (R) medium dan dapat dirumuskan:

$\mathrm{V}=\mathrm{I} . \mathrm{R}$

Prinsip dasar yang digunakan pada alat ini yaitu adalah dengan menginjeksikan arus listrik ke dalam bumi. Setelah out mengamati beda potensial $(\Delta V)$ dan arus (I) yang terbentuk melalui dua buah elektroda yang telah ditempatkan di tempat lain. Perbedaan antar potensial dan arus ini akan menghasilkan suatu nilai ahanan jenis. Perbedaan nilai tahanan jenis dapat merfleksikan keadaan di bawah permukaan bumi.

Pada teknik pengolahan data, data pada beda potensial $(\Delta V)$ dan arus (I) yang didapat dari pengukuran akan dihitung sehingga diperoleh nilai tahanan jenis semu $\left(\rho_{\mathrm{a}}\right)$. Menurut Telford (1990) [1] dan Reynolds (1997) [2] tahanan jenis semu dapat dihitung berdasarkan rumus :

$\rho=K=\frac{\Delta V}{I}$

dimana :

$\rho \quad=$ tahanan jenis semu

$\mathrm{K} \quad$ = factor geometri

$\Delta V \quad=$ beda potensial antara kedua elektroda

I $\quad=$ kuat arus yang diinjeksikan

\section{B. Konfigurasi Wenner-Schlumberger}

Konfigurasi yang akan digunakan yaitu Wenner-Schlumberger, konfigurasi dengan system aturan spasi yang konstan dengan catatan factor " $n$ " untuk konfigurasi ini adalah perbandingan jarak antara elektroda C1-P1 (atau C2-P2) dengan spasi antara P1-P2 seperti pada Gambar 2.6. Lalu, jika jarak antar potensial (P1 dan P2) adalah $a$ maka jarak antar elektroda arus (C1 dan $\mathrm{C} 2$ ) adalah $2 \mathrm{na}+a$. Proses penentuan resistivitas menggunakan 4 buah elektroda yang diletakkan dalam sebuah garis lurus. 


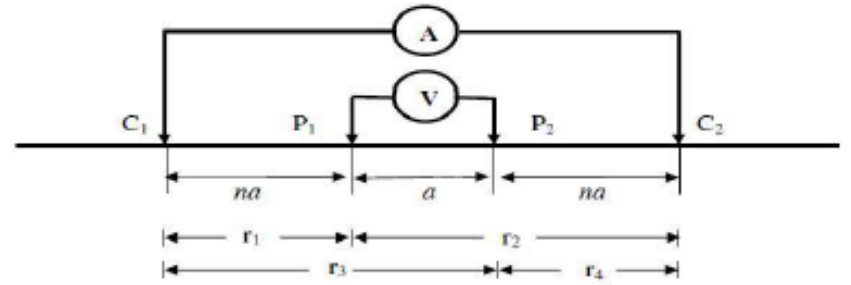

Gambar 1 Dua elektroda arus dan dua elektroda potensial pada permukaan homogeny isotropis dengan tahanan jenis $\rho$ (Bahri, 2005). [3]

\section{METODOLOGI PENELITIAN}

Metodologi penelitian dari penelitian ini yaitu dengan menggunakan pengukuran geolistrik metode Resistivitas 2D dan konfigurasi Wenner-Sclumberger. Dari hasil yang didapatkan dari metode Resistivitas 2D, akan dilakukan perbandingan dengan hasil penampang Induced Polarization. Dibawah adalah diagram alir yang digunakan

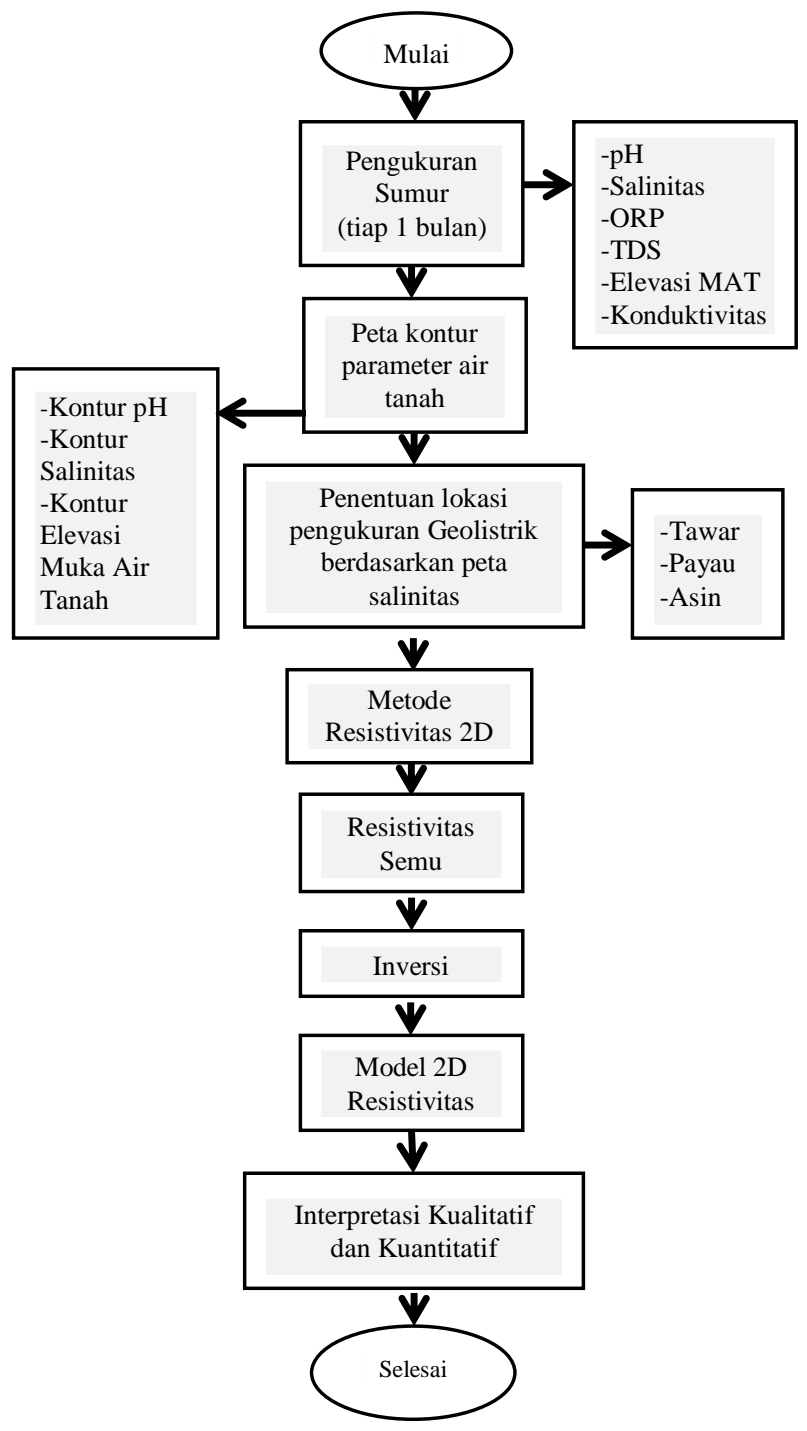

Gambar 2. Diagram Alir Penelitian
IV. HASIL DAN PEMBAHASAN

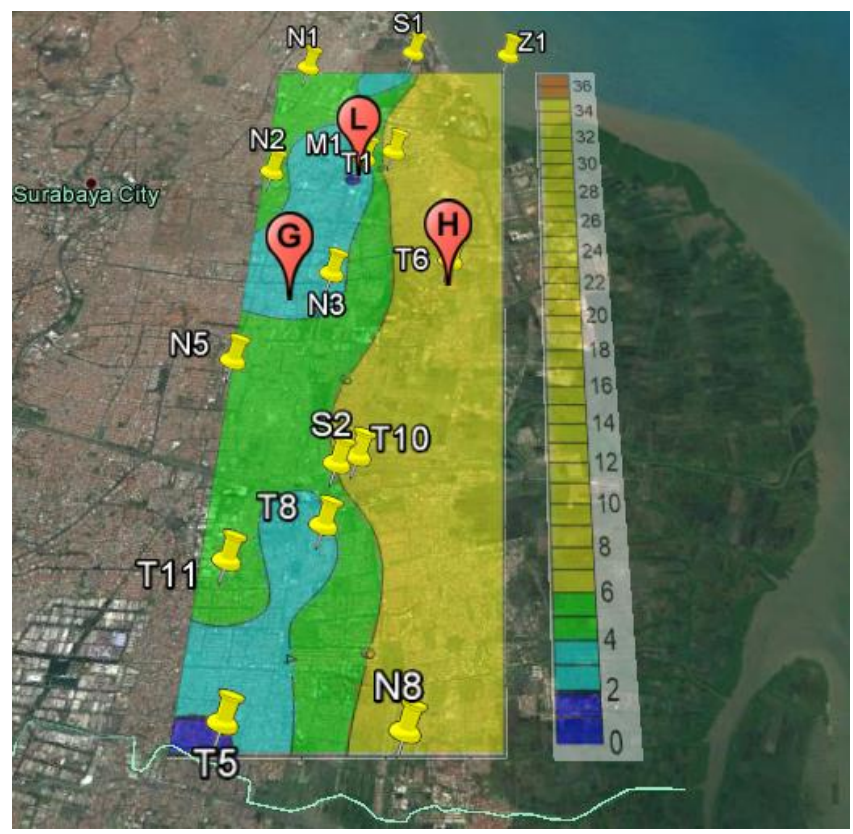

Gambar 3 Desain Akuisisi

Pengambilan data geolistrik telah dilakukan di tiga lokasi yang berbeda. Penentuan lokasi berdasarkan pada dugaan awal bahwa pada tiap-tiap lokasi tersebut memiliki dampak dari intrusi air laut yang berbeda-beda. Ini didasarkan dari pengukuran parameter air sumur yang menghasilkan nilai berbeda-beda dalam satuan kualitas salinitasnya. Pada lokasi yang diduga intrusi terletak pada lokasi Sutorejo (L).

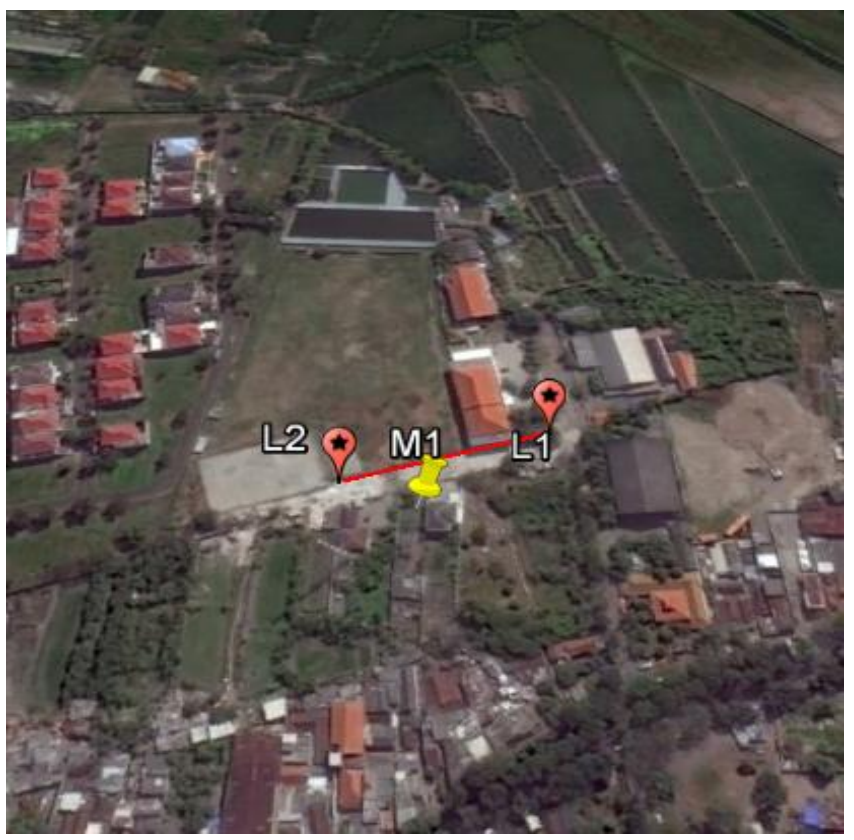

Gambar 4. Lokasi Pengukuran Geolistrik Sutorejo

Dari hasil pengolahan Resistivitas 2D dapat dilihat pada Gambar 4 menunjukkan nilai dan lapisan yang bervariasi. Lapisan pertama mempunyai nilai resistivitas yang tinggi yaitu 
(6.81-63.1 ohm.m) pada kedalaman 0.6-3 meter yang ditunjukkan oleh warna kuning hingga ungu, bahwa pada lapisan ini dapat diduga sebagai akuifer yang bercampur dengan pasiran. Pada bagian tengah sampai timur laut (L1) ini didominasi oleh nilai resistivitas yang cukup rendah. Dapat dilakukan pendugaan bahwa adanya kemungkinan intrusi air laut berasal dari arah utara. Dibawah lapisan yang pertama terdapat lapisan yang diduga sebagai lempung yang berasosiasi denga pasiran pada kedalaman 3-8 meter dengan memiliki ketebalan 5 meter. Nilai resistivitas dari lapisan ini adalah (0.0260-0.734 ohm.m) sedangkan untuk nilai dari chargeabilitas memiliki nilai yang cukup tinggi (0.562-1.08 msec). Untuk lapisan dibawah ini yaitu diduga sebagai lapisan lempung dengan nilai resistivtias (0.734-6.81 ohm.m).

Meskipun daerah pengukuran Sutorejo ini jaraknya berdekatan dengan pantai sekitar $3 \mathrm{~km}$, namun pada sumur yang dilakukan dekat lokasi pengukuran geolistrik ini mempunyai kualitas air dengan salinitas yang kecil sebesar $1.63 \mathrm{ppt}$ sehingga air ini masih layak untuk dikonsumsi. Pada daerah ini terlihat bahwa terdapat batas intrusi, sedikit bergeser kearah timur laut maka akan ditemui air dengan salinitas payau dan asin. Dapat dimungkinkan bahwa daerah ini memiliki kualitas air yang bagus karena merupakan daerah zona tangkapan (discharge) dari barat daya. Serta pada daerah penelitian ini memiliki kontur muka air tanah cukup curam, hal ini mengindikasikan bahwa aliran air cukup banyak dari arah barat daya. Sehingga kualitas air pada daerah ini cukup layak untuk dikonsumsi. Jika dilakukan perbandingan, nilai dari pengukuran resistivitas pada kedalaman 0.6-3 meter yang diduga sebagai zona akuifer akan terlihat bahwa daerah sebelah timur laut mempunyai memiliki nilai resistivitas yang lebih kecil dibanding pada daerah barat daya. Dan dimungkinkan bahwa pada nilai resistivitas $(6.81 \mathrm{ohm} . \mathrm{m})$ ini merupakan air laut. Namun pada data IP menunjukkan adanya perbedaan chargeabilitas yang terdapat pada bagian timur laut yang memiliki nilai yang lebih besar $(0.302 \mathrm{msec})$ jika dibandingkan pada bagian barat daya $(0.0418 \mathrm{msec})$.

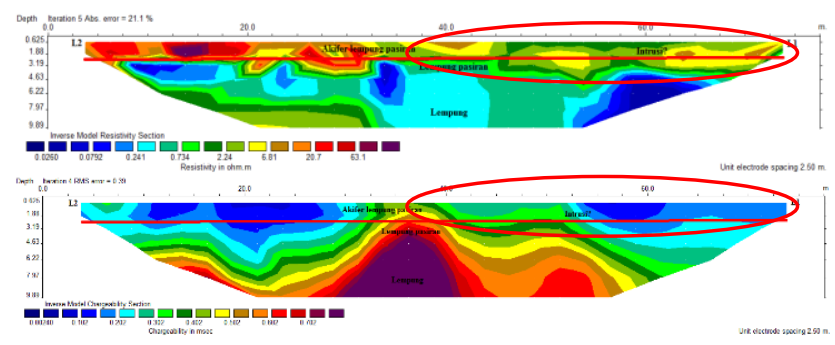

Gambar 5. Hasil Perbandingan Penampang Resistivitas 2D dan Induced Polarization

\section{KESIMPULAN}

Kesimpulan yang dapat diambil dari penelitian ini antara lain:

1. Dari pengukuran metode Resisitivitas 2D ini menghasilkan data penampang yang cukup baik dalam penelitian ini. Zona intrusi air laut dapat terlihat pada lokasi Sutorejo dengan nilai resistivitas $6.31 \mathrm{ohm}$.m. Hasil ini juga didukung dari data IP dan data sumur sekitar lokasi pengukuran.
2. Untuk daerah ITS seharusnya menunjukkan adanya zona akuifer air asin, namun nilai resistivitas pada zona yang diduga terlampau besar. Dugaan ini disebabkan karena terdapatnya asosiasi anatra akuifer dengan lempung. Namun nilai chagreabilitas telah menunjukkan hasil yang lumayan baik sebesar $0.202 \mathrm{msec}$ yang berarti bahwa adanya zona akuifer air asin pada daerah tersebut.

3. Pada penelitian ini, metode resistivitas 2D sangat baik dalam identifikasi intrusi air laut. Hal ini juga didukung dari penampang IP yang baik.

\section{DAFTAR PUSTAKA}

[1] Telford, W. M. (1990). Applied Geophysics Second Edition. Melbourne: Cambridge University Press.

[2] Raynold, J.M, 1997. Introdution to Applied and Eviromental Geophysics. John Willey and Soon Ltd.

[3] Bahri. 2005. Hand Out Mata Kuliah Geofisika Lingkungan dengan Topik Metode Geolistrik Resistivitas. FMIPA ITS, Surabaya. 